\title{
Fire as a primary event of accident domino sequences: the case of BLEVE
}

\author{
Behrouz Hemmatian, Eulàlia Planas-Cuchi and Joaquim Casal* \\ Centre for Studies on Technological Risk (CERTEC). \\ Department of Chemical Engineering. ETSEIB, Universitat Politècnica de Catalunya. \\ Diagonal 647. 08028-Barcelona. Catalonia, Spain.
}

\begin{abstract}
The domino sequences found in major accidents have been analyzed for a large set of cases (330); the first event triggering the domino effect was an explosion or a fire, both with approximately the same contribution; the same proportion has been found when all domino effect steps were considered. Although fire effects usually reach a distance much shorter than those of an explosion, as fire is the most frequent major accident it is often found as the first step of domino sequences. This is especially true in the case of BLEVEs. Both in fixed plants and in the transportation of hazardous materials, in the event of a fire, if flames affect a vessel and the fireproofing layer has been damaged, a BLEVE can occur at any moment. 127 BLEVE accidents involving domino effect have been analyzed. It has been found that fire is significantly more frequent than explosion, both in triggering the domino effect sequence and in intermediate steps. The time to failure can range from one minute or even less up to several hours, an aspect that should be very important for the management of the emergency. A set of conclusions are inferred from this survey.
\end{abstract}

\section{Keywords}

Domino effect, time to failure, explosion, historical analysis

\section{Introduction}

The interest on the domino effect has increased significantly in recent years. The experience has shown that in many major accidents, this effect has played an important role in enlarging the severity of the accident both in fixed plants and in the transportation of hazardous materials by road or rail. Thus, a first event -a fire, an explosion-can lead after a relatively short time to a second one, and then to a third one. Depending on the circumstances (for example, the congestion of a plant or the number of rail cars involved in a derailment) this effect can lead to a catastrophic series of explosions and/or fires or toxic releases. This can have severe consequences on the population and, more frequently, on firefighters, increasing as well the materials losses.

The first event in a domino effect sequence is usually an explosion or a fire: thermal radiation or flames impingement, or overpressure and ejected fragments, can damage equipment, originating a further loss of containment and, therefore, the escalation of the accident. These two accidents have approximately the same contribution when large sets of cases are analyzed. However, in the specific case of BLEVEs the situation changes significantly, fire having a much more significant role.

If a vessel containing a pressurized liquid is subjected to the effects of a fire, there is a certain possibility that, depending on the circumstances, it explodes after a time. This can happen even if the vessel is equipped with active or passive protection, and with pressure relief valves; and it can occur almost immediately or after more than one hour from the

\footnotetext{
* Corresponding author. Tel: +34 934016704

E-mail address: joaquim.casal@upc.edu

Postal address: ETSEIB-UPC. Diagonal 647.08028-Barcelona,Spain.
} 
starting of the fire. BLEVEs are important because this is a type of accident that happens from time to time, both in fixed plants or in the transportation by rail or road; and, unfortunately, we must accept that it will continue occurring, as the number of units which can undergo it is very high and still increasing, especially in transportation. However, a better knowledge of this phenomenon can help both in decreasing its frequency and in reaching a better management of the emergency.

This paper analyzes the incidence of fire as a primary event, as well as the domino effect sequences found in this type of accident.

\section{Most common events triggering or maintaining domino sequences}

As emphasized by several authors, the most frequent major accidents in both industrial plants and in the transportation of hazardous materials are fires. In an extensive historical survey performed on 5325 accidents occurred in chemical plants and in transportation, Vílchez et al. [1] found the following proportion for fire/explosion/gas cloud: 3.6 / 3 / 1. Another analysis on 1932 accidents occurred during the transportation by road and rail [2] showed that 1 out of every 3.5 led to a fire and 1 out of every 9.5 accidents led to an explosion. Therefore, fire can be considered the most frequent major accident.

If accidents involving domino effect are considered, an interesting aspect is the analysis of the initiating step, i.e., the primary event of the domino effect sequence. Here, fire and explosion are the dominant issues, their physical effects being clearly aggressive with respect to equipment. Instead, toxic clouds, even though they can affect relatively large areas, cannot provoke any significant damage to installations.

Diverse authors have recently analyzed the respective contributions of explosions and fires as primary events in a domino effect. Darbra et al. [3] analyzed 225 domino effect accidents occurred in process/storage plants and in the transportation of hazardous materials, and found that fire was the initiating step in 52\% of cases and explosion (of any type) in 48\%. Abdolhamizadeh et al. [4] studied 224 accidents, in which fire was the initiating event in $43 \%$ of cases and explosion in 57\%. More recently, Hemmatian et al. [5] performed a historical survey on 330 domino effect accidents, finding that explosion was the primary event in 53\% of cases and fire in $47 \%$.

This last survey, which analyzed the largest set of domino effect accidents, gives an interesting opportunity to see the significance of fire as a domino effect agent, both in primary and secondary levels. Figure 1 (modified from [5]), shows that secondary-level accidents were distributed as follows: 194 fires, 127 explosions and 9 toxic releases; among accidents which generated a third-level domino accident, 35 were fires and 13 explosions. If all domino effect phenomena in this tree are taken into account, it is seen that 190 were originated by fires and 188 by explosions. 


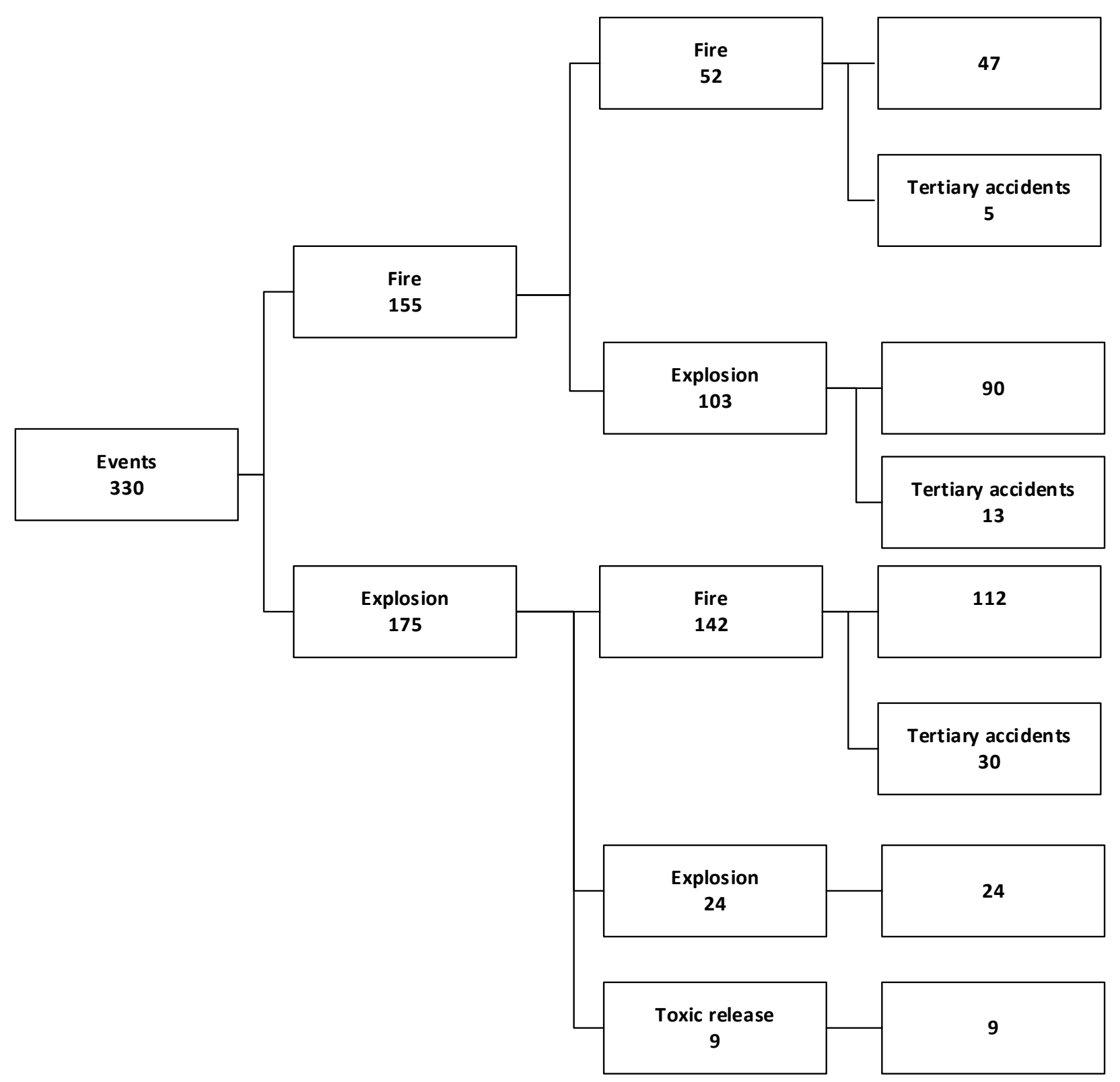

Fig. 1. Fire and explosion in triggering and maintaining domino effect sequences

(modified from [5]).

Thus, from these data it can be concluded that the respective contributions of fire and explosion in triggering or maintaining a domino effect sequence are similar. This conclusion could seem not to be in good agreement with the aforementioned fact that fires are clearly more frequent than explosions. However, it must be taken into account that the reach of the destructive effects of an explosion -blast and ejected fragments- is usually significantly larger than that of the effects (flames engulfment, thermal radiation) of most fires; thus, the possibility that an explosion damages other equipment is often higher than that associated to a fire. 


\section{Effects of fire on a vessel}

When a vessel is subjected to a fire, its effects will depend on the type of fire, especially on the thermal flux released, and on whether the equipment is exposed only to thermal radiation or there is flames impingement. As for the consequences, they will depend on the duration of the fire and on the equipment features: design (shape, wall thickness), filling degree and existence of protective measures.

\subsection{Pool and tank fires}

Pool and tank fires can last long time; if their thermal radiation reaches another relatively close equipment, unless this is adequately protected -both thermal insulation and water deluge can be a good protection in this situation- the conditions for failure could be reached.

In this type of fires, the combustion is rather bad due to poor air entrainment (the flow velocity in the flames is usually less than $10 \mathrm{~m} \mathrm{~s}^{-1}$ [7]). Flames are composed of relatively bright zones, with a high concentration of incandescent soot, and other zones covered by black smoke; both zones contribute to thermal radiation, bright zones having the highest emissive power (E). For the non-luminous (smoke covered) zones, Muñoz et al. [8], working with gasoline and diesel oil, found a value of $E_{\text {soot }}=40 \mathrm{~kW} \mathrm{~m}^{-2}$, independent of the pool diameter and of the type of fuel. For the luminous, bright zones, they found $\mathrm{E}_{\text {lum }}$ values ranging between 80 and $120 \mathrm{~kW} \mathrm{~m}^{-2}$, depending on the pool diameter and the type of fuel. The fraction of the fire surface covered by the luminous flame depends on the type of fuel, although an approximate value of 0.4 can be assumed; this would imply an approximate value for the whole fire surface of $\mathrm{E}=60 \mathrm{~kW} \mathrm{~m}^{-2}$. Moorhouse and Pritchard [9] suggested that with large pool fires of hydrocarbons, excluding liquefied gases, $\mathrm{E}$ is unlikely to exceed this value. Other values have also been proposed: API 521 [10] suggests $80-100 \mathrm{~kW} \mathrm{~m}^{-2}$; Mizner and Eyre [11] obtained surface emissive powers of 35 $\mathrm{kW} \mathrm{m}^{-2}$ for kerosene, $48 \mathrm{~kW} \mathrm{~m}^{-2}$ for LPG and $153 \mathrm{~kW} \mathrm{~m}^{-2}$ for LNG.

However, the radiation intensity decreases quickly as the distance from the flame surface increases, and the heat load on a given equipment will usually be much lower than these values.

If there is flame engulfment of an equipment, heat transfer will be the sum of two contributions, radiation and convection. Different values have been proposed; heat fluxes in the range of $95-130 \mathrm{~kW} \mathrm{~m}^{-2}$ have been measured for kerosene [12], $80-150 \mathrm{~kW} \mathrm{~m}^{-}$ ${ }^{2}$ for JP-4 [13], 100-180 $\mathrm{kW} \mathrm{m}^{-2}$ as a general range for liquid hydrocarbons and $150-250$ $\mathrm{kW} \mathrm{m}{ }^{-2}$ for LPG pool fires $[14,15]$. This can lead to rather high temperature increase rates of the vessel wall above the liquid level.

If there is flame impingement, deluge systems require high flow rates; adequate thermal insulation can give a good protection.

\subsection{Jet fires}

Jet fires thermal characteristics depend on the fuel and on the outlet velocity. Low pressure releases of liquid or two-phase mixtures give low velocity flames and bad combustion, a situation relatively close to that of a pool fire. If the velocity is high, air entrainment is important and this improves the combustion; however, with two-phase flow, the flame is still sooty and bright and the radiation mechanism dominates. Instead, with gas sonic flow -gas jet fires are often sonic and very turbulent- the combustion is very good and the flame is almost transparent, convection being much more important than radiation. This behavior has an important influence on the value of the flame surface 
emissive power; for propane, Palacios et al [16] obtained values of approximately $\mathrm{E}=80$ $\mathrm{kW} \mathrm{m}^{-2}$ for gas jets and $\mathrm{E}=230 \mathrm{~kW} \mathrm{~m}^{-2}$ for two-phase flow jet fires.

The thermal radiation intensity decreases significantly with the distance, but if there is impingement of the flames on a surface, very high heat fluxes occur. Impinging on a solid surface modifies significantly the shape of the flame, increasing the area of contact with the equipment. Accurate values cannot be predicted and a wide range of heat fluxes has been proposed; the following ones can be assumed [17]:

- natural gas: 50 - $300 \mathrm{~kW} \mathrm{~m}^{-2}$; average: $200 \mathrm{~kW} \mathrm{~m}^{-2}$

- propane gas, sonic: $300 \mathrm{~kW} \mathrm{~m}^{-2}$

- propane, two-phase flow: $150-220 \mathrm{~kW} \mathrm{~m}^{-2}$

- propane, two-phase flow, low velocity: $150 \mathrm{~kW} \mathrm{~m}^{-2}$.

If these heat fluxes impinge on a non-wetted wall, the temperature increase is so quick that the vessel can fail in a very short time.

\subsection{Fireballs}

The thermal radiation intensity from a fireball can be very strong at short distances. Flames surface emissive power depends on the fuel and is usually significantly higher than that of a pool fire, as practically all the fireball surface is covered by bright flames. Moorhouse and Pritchard [9] suggested a range of $150-300 \mathrm{~kW} \mathrm{~m}^{-2}$, although it can be as high as $350 \mathrm{~kW} \mathrm{~m}^{-2}$ for LPG. As the duration is short, protected equipment subjected to it will not fail; unprotected equipment could fail in some cases, but the probability is rather low due to the short exposure time. If there is flame impingement, heat fluxes can be in the range $200-350 \mathrm{~kW} \mathrm{~m}^{-2}[18,19]$. In this case, water deluge systems are not efficient due to the turbulence of flames, but fireproofing layers are efficient; again, the contact time will be generally very short as the fireball will rise from the ground level, and the probability of failure must be considered rather low.

\subsection{Flash fires}

The contact time with the equipment is so short that the probability of originating a domino effect is usually negligible, except for floating roof tanks (in this case, a flash fire could originate a tank fire) [6].

A summary of the approximate ranges of heat fluxes and surface emissive power for the diverse types of fire can be seen in Table 1.

Table 1. Approximate ranges of heat fluxes and surface emissive power.

\begin{tabular}{lll}
\hline Type of fire & $\mathrm{E}, \mathrm{kW} \mathrm{m}^{-2}$ & $\begin{array}{l}\text { Flame engulfment/impingement } \\
\text { heat flux, } \mathrm{kW} \mathrm{m}^{-2}\end{array}$ \\
\hline Pool, tank & Hydrocarbons: $40-100$ & $80-180$ \\
& LNG: $150-200$ & $180-260$ \\
& LPG:50-120 & $150-250$ \\
& Two-phase: 230 & $150-220$ \\
Jet (LPG) & Gas: 80 & $200-350$ \\
& 150-350 & -- \\
Fireball & LNG, LPG: $125-280$ & -- \\
Flash fire & & \\
\end{tabular}




\section{Heating rate of vessel wall}

When a vessel undergoes the effects of a fire, the situation can change dramatically depending on two circumstances: i) the vessel wall has or not a thermal insulation layer; ii) the vessel wall is in contact with a liquid or with a vapor.

The existence of a passive protection -a thermal insulation layer- should in principle imply that the vessel wall temperature will not increase up to dangerous values. However, if this protection does not exist or -as often happens- it has been destroyed by a mechanical action (erosion by a turbulent jet, the impact by a fragment from an explosion, a traffic accident in the case of a road or rail tanker), the wall is directly exposed to the fire effects.

In such circumstances, the situation can again significantly change depending on whether the wall is wetted by the liquid contained in the vessel or it is in contact with the vapor above the liquid level.

If the wall is wetted by liquid, its temperature will be close to that of the liquid and thus it will be protected and will not lose strength. However, if the wall is above the liquid level, i.e. it is in contact with the vapor, cooling by convection will be very poor and its temperature will increase rather quickly. The wall heat-up will be especially important if the vessel is engulfed by the flames. Figure 2 shows the evolution of wall temperature for an empty vessel located on a pool fire [20]. With the initial development of the fire, the wall temperature increases quickly $\left(3.5^{\circ} \mathrm{C} \mathrm{s}^{-1}\right.$ for the hexane pool, $5.8^{\circ} \mathrm{C} \mathrm{s}^{-1}$ for the kerosene pool); in a second stage, with a fully developed fire, fire-induced wind reduced somewhat the wall heating rate: $1.3{ }^{\circ} \mathrm{C} \mathrm{s}^{-1}$ for the hexane pool, $3.6{ }^{\circ} \mathrm{C} \mathrm{s}^{-1}$ for the kerosene pool. In all cases the rate at which the temperature rises is very high, implying that in very short time the wall can be heated in such a way that, due to the weakening of the material, it will not stand the inside pressure.

a)

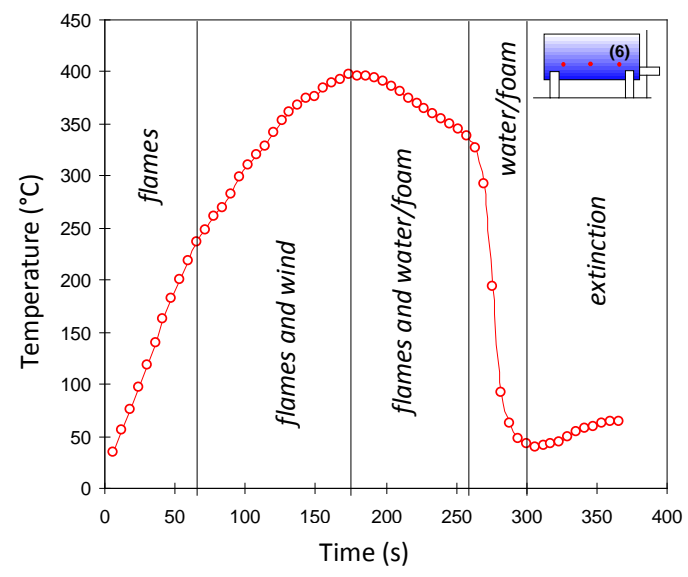

b)

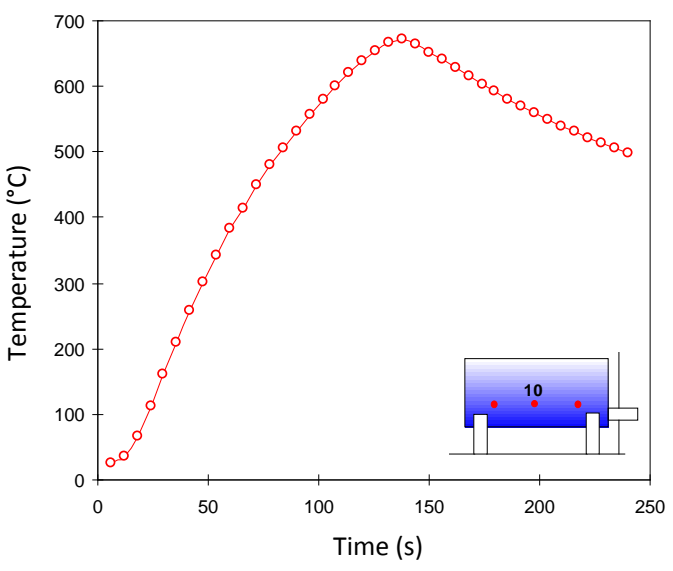

Fig. 2. Temperature evolution as a function of time in a non-wetted wall of a vessel engulfed in a pool fire: a) pool fire of hexane, $4 \mathrm{~m}^{2}$, lower lateral wall; b) pool fire of kerosene, $12 \mathrm{~m}^{2}$, lower lateral wall [20].

The pressure inside the vessel will increase due to the fire heating of the wall surface wetted by the liquid [21]. For example, a rail tank car filled to 94\%, engulfed in a hydrocarbon pool fire, was pressurized up to the safety relief valve set pressure in approximately 2 minutes [22]. 
However, even if the pressure relief valve opens, it could not prevent the vessel explosion if the vapor space wall has been heated up to too high temperatures; furthermore, the release through the pressure relief valve implies that the liquid level continuously decreases, and thus the vapor surface impinged by fire increases more and more. Of course, if the valve action delays the explosion, the mass involved in it will be smaller and the effects will be less severe.

The aforementioned heating rates can be significantly higher if there is impingement of the flames from a highly turbulent jet fire, as in this case the heat flux will be much more important.

\section{BLEVEs and domino effect sequences}

A historical analysis was performed on accidents involving a BLEVE event. The Major Hazard Incident Data Service [22] database was used, as well as Analysis, Research and Information on Accidents [3], Major Accident Reporting System [4] and Failure and Accidents Technical Information System [25]. The lack of information in some accidents was fulfilled by getting assistance of other available resources like the U. S. National Transport Safety Board-Chemical Safety Board [26] and the U. S. National Fire Protection Association [27].

To establish if an accident was or not a BLEVE, here the definition of BLEVE proposed by CCPS [28] was applied: "a sudden loss of containment of a pressure-liquefied gas existing above its normal atmospheric boiling point at the moment of its failure, which results in rapidly expanding vapor and flashing liquid”. This definition is quite similar to the one published by Walls (one of the three authors who first used the BLEVE acronym): a failure of a major container into two or more pieces, occurring at a moment in time when the contained liquid is at a temperature well above its boiling point at normal atmospheric pressure" [29]. This means that no distinction was considered on the basis of the material temperature being or not higher than the superheat limit. It should be clear that a BLEVE is just a mechanical explosion (its effects being blast and ejected fragments) and not a fireball, even though if the material released by the BLEVE is flammable, a fireball will usually occur immediately after the explosion.

The criteria used for the selection of accidents were the following:

- Only accidents occurred after $1^{\text {st }}$ January 1960 were taken into account; before this date both the industrial plants and the transportation were essentially different from the present ones.

- The survey considered accidents occurred in process plants, in storage areas or in transportation (road, rail and ship); it also included accidents that had occurred because of natural events such as earthquakes or floods.

- Accidents occurred in military premises were not considered.

Finally, a set of 167 BLEVE accidents was selected according to these criteria. The analysis of these cases allowed the identification of those accidents in which a domino effect sequence occurred. In 40 accidents, a BLEVE occurred as a single accident; in 127 cases a domino sequence was found and the corresponding information was statistically treated.

Table 2. General origin of BLEVE accidents with domino effect 


\begin{tabular}{lcc}
\hline General origin & No. of accidents & Overall percentage (\%) \\
\hline Transport & 60 & 47 \\
Storage area & 39 & 31 \\
Transfer & 22 & 17 \\
Process plant & 12 & 9 \\
Domestic/commercial premises & 6 & 5 \\
Other & 4 & 3 \\
Total & 143 & 112 \\
\hline
\end{tabular}

The type of plant or activity in which these 127 accidents occurred can be seen in Table 2; the overall number of accidents (143) is larger than that of real accidents because some of them can be included in two different origins (for example, "transfer" and "storage area”). Practically half of the accidents occurred during transportation, followed by storage, transfer and process plants. It is interesting to note the high contribution of transfer operations (22 accidents); this had been already found in other historical surveys $[1,5]$. As for the specific origin (Table 3), rail tankers were the most common, followed by pressurized storage vessel and road tanker. Here again there are some misleading data; for example, in Table 2, 60 accidents correspond to "transport", while in Table 3 rail and road tanker plus ship accidents sum 65. This is due to the coincidence of both "transfer" and "transport" in several accidents in the MHIDAS database, which criterion has been kept here.

Table 3. Specific origin of BLEVE accidents with domino effect

\begin{tabular}{lcc}
\hline Specific origin & No. of accidents & Percentage (\%) \\
\hline Rail tanker & 40 & 31 \\
Pressurized storage vessel & 24 & 19 \\
Road tanker & 22 & 17 \\
Portable transport containers & 17 & 13 \\
On plant pipes and associated valves & 6 & 5 \\
Atmospheric pressure storage vessels & 5 & 4 \\
Heat exchangers & 4 & 3 \\
Reactor & 3 & 2 \\
Ship & 3 & 2 \\
Hose & 3 & 2 \\
Other & 8 & 7 \\
Total & 135 & 105 \\
\hline
\end{tabular}

The substances involved in the accidents have been summarized in Table 4. The resulting overall number of accidents (199) is again much larger than that of real accidents because in many of them diverse substances were involved (e.g., in a train accident occurred in 2000 in Louisiana, dichloropropane, toluene diisocyanate, sodium hydroxide, ethylene oxide, acrylic acid and methyl chloride were involved). LPG was clearly the most frequent substance, followed by oil and other hydrocarbons; only four cases were found in which LNG was involved.

Table 4. Substances involved in BLEVE accidents with domino effect

\begin{tabular}{lcc}
\hline Substance & No. of accidents & Percentage (\%) \\
\hline LPG & 90 & 71 \\
Oil/Gasoline/Petrol/Diesel/Kerosene & 14 & 12
\end{tabular}


Vinyl Chloride

Ethylene Oxide

LNG

Propylene

Other chemical substances

Total
10

7

4

4

70

199

As for the general cause of the accidents (Table 5), practically two over five of them were due to an impact; this cause was found mainly in transportation. This was followed by other external events, mechanical failure and human factor, respectively.

Table 5. General causes of accidents

\begin{tabular}{lcc}
\hline General cause & No. of accidents & Percentage (\%) \\
\hline Impact failure & 52 & 47 \\
External events & 39 & 35 \\
Human factor & 31 & 28 \\
Mechanical failure & 30 & 28 \\
Instrument failure & 5 & 5 \\
Violent reaction & 5 & 5 \\
Services failure & 1 & 1 \\
Total & 163 & 148 \\
\hline
\end{tabular}

The significance of fire in the BLEVE sequences can be seen in Fig. 3. In 88 cases (69\%) a fire was the first step, while in 33 cases the first event was directly a BLEVE. A typical scenario was a road or rail accident with a release of a flammable substance, quickly ignited; the flames travelled back to the release source, leading to a jet fire which, after a certain time, provoked the explosion of the vessel. If all domino effect steps in the analyzed sequences are considered, then 97 fires and 57 explosions leading to another event are found. Here again is seen the larger contribution of fire as compared to that of explosion. 


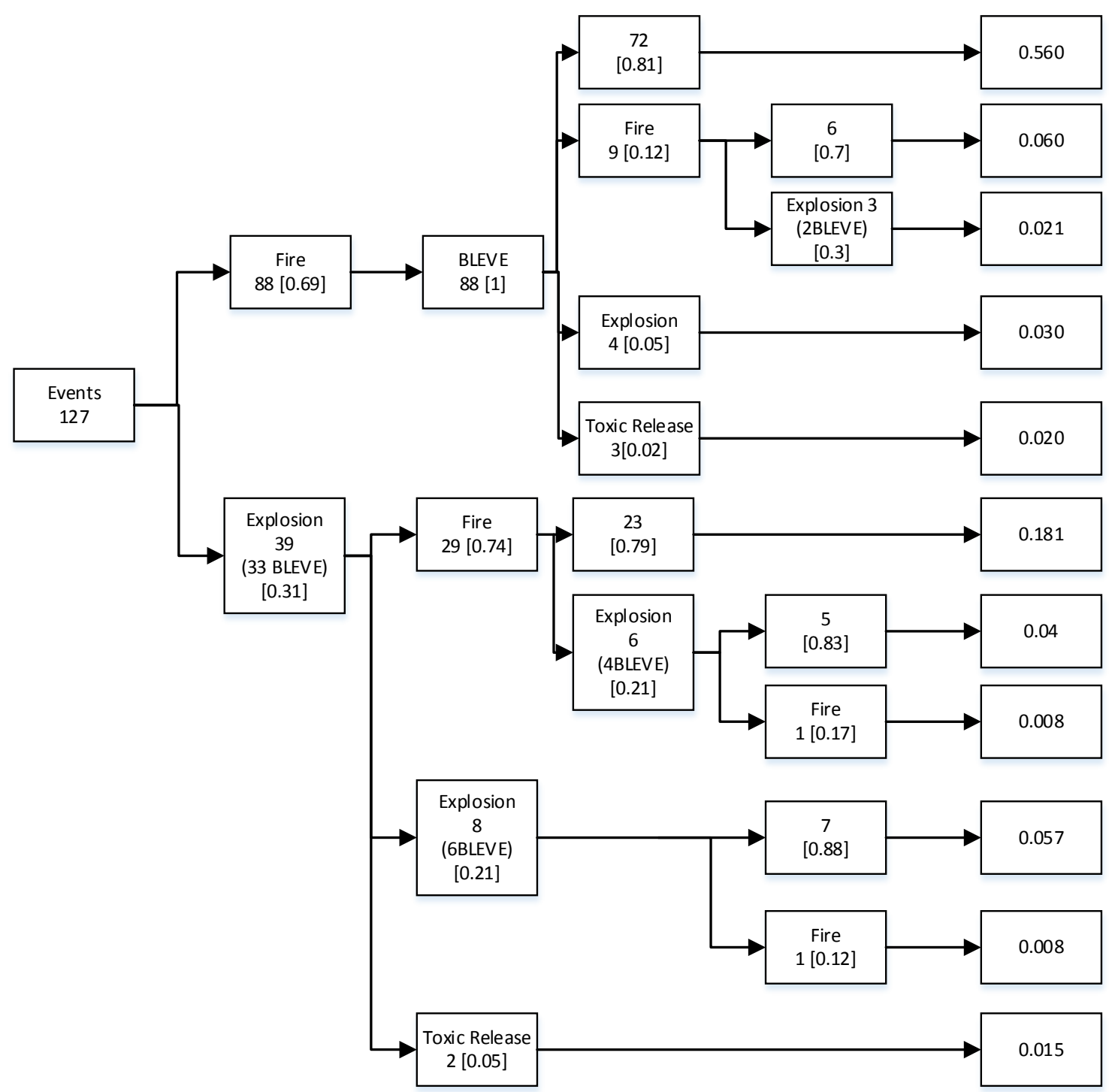

Fig. 3. Domino effect sequences in BLEVE accidents.

The explosion following the fire was in most cases the closing event of the sequence; this is a logical sequence in the case of one road tanker. However, in a few ones it led to another explosion or to another fire. In those accidents in which the accidental sequence started with a BLEVE, this could lead to a fire (in most cases) or to another explosion. Of course, the complexity of the possible sequences depends on the plant arrangement or on the number of rail tankers involved in the accident. As a whole, the sequence fire $\rightarrow$ explosion was found in 97 cases in the event tree (Fig. 3), while explosion $\rightarrow$ another event occurred only in 57 cases. It should also be noted that in a few, very unusual cases, the vessel can fail without exploding but releasing a large jet fire [30].

\section{Time to failure}

When an equipment is subjected to the effects of a fire, the time to failure is a very important aspect from the point of view of emergency management. Thirty years ago it was generally believed that when a pressurized vessel was subjected to direct contact with flames -a situation that could originate an explosion- about 25-30 minutes were available to try to solve the situation; after that time, the explosion could occur at any moment and therefore firefighters should move away. This false belief costed the life of many people, 
most of them firefighters. It is now well known that in the aforementioned situation, depending on the circumstances, the explosion can occur after a few minutes from the start of the fire action, or even after a shorter time. In the San Juanico accident (Mexico, 1984), the first BLEVEs occurred 70 seconds after the first jet fires appeared; in the accident occurred in Nijmegen (The Netherlands) in 1978, a tanker of LPG exploded at a filling station just 3 minutes after fire started underneath during unloading. However, the time to failure can be significantly higher: in the accident occurred in Zarzalico (Spain, 2011), an LNG road tanker was exposed to a very strong fire during approximately seventy minutes before the explosion occurred [31]. Table 6 gives the time to failure for a series of accidents involving fire $\rightarrow$ BLEVE domino sequences [22]. 
Table 6. Time to failure for different cases (fixed plants and transportation).

\begin{tabular}{|c|c|c|c|c|}
\hline Date & Place & Sequence & Material & Time to failure \\
\hline 1984 & Mexico & VCE $\rightarrow$ Jet fire $\rightarrow$ BLEVE $\rightarrow$ Fire & LPG sphere & 70 seconds \\
\hline 1978 & Netherlands & Fire $\rightarrow$ BLEVE & LPG & 3 minutes \\
\hline 1961 & USA & Fire $\rightarrow$ BLEVE $\rightarrow$ Fire & LPG cylinder & 10 minutes \\
\hline 1974 & USA & Fire $\rightarrow$ BLEVE & LPG & 13 minutes \\
\hline 1982 & USA & Fire $\rightarrow$ BLEVEs & LPG & 15 minutes \\
\hline 1978 & USA & Fire $\rightarrow$ BLEVE & $\begin{array}{l}\text { Isobutane, propane, } \\
\text { propylene, butane }\end{array}$ & $\begin{array}{l}20 \text { minutes, series } \\
\text { of explosions }\end{array}$ \\
\hline 2006 & Italy & Fire $\rightarrow$ BLEVE & LPG cylinder & 25 minutes \\
\hline 1972 & USA & Fire $\rightarrow$ BLEVE & LPG & 40 minutes \\
\hline 2011 & Japan & Fire $\rightarrow$ BLEVE & LPG sphere & 1 hour \\
\hline 1966 & France & Fire $\rightarrow$ BLEVE $\rightarrow$ Fire $\rightarrow$ Expl. & LPG sphere & 1.5 hours \\
\hline 1980 & USA & Fire $\rightarrow$ BLEVE & Petrol road tanker & 3 minutes \\
\hline 1970 & USA & Fire $\rightarrow$ BLEVEs & LPG rail cars & $\begin{array}{l}\text { First car: } 5 \text { min. } \\
6 \text { rail cars in } 40 \\
\text { minutes }\end{array}$ \\
\hline 1970 & USA & Fire $\rightarrow$ BLEVEs & LPG & 15 minutes \\
\hline 1987 & Australia & Fire $\rightarrow$ BLEVE & LPG rail tanker & 15 minutes \\
\hline 1974 & Spain & Fire $\rightarrow$ BLEVE & $\begin{array}{l}\text { Ethylene cryogenic } \\
\text { trailer }\end{array}$ & 20 minutes \\
\hline 1989 & USA & Fire $\rightarrow$ BLEVE $\rightarrow$ Fire & $\begin{array}{l}\text { Peroxide, } \\
\text { polyethylene rail } \\
\text { cars }\end{array}$ & $\begin{array}{l}\text { Peroxide car: } 20 \\
\text { minutes; } \\
\text { polyethylene car: } \\
6 \text { hours }\end{array}$ \\
\hline 2002 & Spain & Fire $\rightarrow$ BLEVE & LNG road tanker & 20 minutes \\
\hline 1972 & USA & FIRE $\rightarrow$ BLEVE & $\begin{array}{l}\text { Propylene road } \\
\text { tanker }\end{array}$ & 25 minutes \\
\hline 1973 & USA & Fire $\rightarrow$ BLEVE & LPG rail car & 30 minutes \\
\hline 1970 & France & Fire $\rightarrow$ BLEVE & Propane tank car & 40 minutes \\
\hline 1971 & USA & Fire $\rightarrow$ BLEVE & $\begin{array}{l}220 \mathrm{~m}^{3} \text { Vinyl } \\
\text { chloride rail tanker }\end{array}$ & 40 minutes \\
\hline 1968 & USA & Fire $\rightarrow$ BLEVE $\rightarrow$ Toxic release & Ethylene oxide & 45 minutes \\
\hline 2011 & Spain & Fire $\rightarrow$ BLEVE & LNG road tanker & 70 minutes \\
\hline 1976 & USA & Fire $\rightarrow$ BLEVE & $\begin{array}{l}\text { Propane, isobutane } \\
\text { rail tankers }\end{array}$ & $\begin{array}{l}\text { Propane tank; } \\
1.5 \text { h later, } \\
\text { isobutane tank }\end{array}$ \\
\hline
\end{tabular}

Diverse circumstances can have a significant influence on the value of the time to failure; for example, it will increase with the mass contained in the vessel; however, two aspects can have a significant influence:

a) Whether the flames impinge on the vessel wall below the liquid level (tank wall being therefore refrigerated by the liquid) or above it; in this later case, if there is no passive protection, wall temperature will increase significantly and its tensile strength will decrease, what can eventually lead to the vessel burst in a relatively short time. 
b) The existence of a protection system. Active or passive protection can be very useful in certain cases to avoid or, at least, delay, the failure of equipment undergoing thermal radiation or flames impingement.

Water deluge can be efficient to protect equipment subjected to pool fires effects, both for radiation exposure or flames impingement, as they are able to maintain a water film on the equipment surface (Table 7). With high momentum jet fires, however, a water deluge system should not be considered a good protection if there is flame impingement, as the high velocity of the jet will probably penetrate the water film and the dry surface will be in contact with the flames [32]. Fixed water monitors could be effective delivering a high flow rate of water just to the flames impingement zone [33].

Table 7. Water application rates from API 2510A [31].

\begin{tabular}{ll}
\hline Exposure to radiant heat (no flame impingement) & $5 \mathrm{~L} \mathrm{~min}^{-2} \mathrm{~m}^{-2}$ \\
Flame impingement (pool fire) & $5-12.5 \mathrm{~L} \mathrm{~min}^{-2} \mathrm{~m}^{-2}$ \\
Flame impingement (jet fire) & $12.5-25.0 \mathrm{~L} \mathrm{~min}^{-2} \mathrm{~m}^{-2}$ \\
\hline
\end{tabular}

However, water deluge systems and water monitors have some practical disadvantages, amongst which the large overall water requirement and corrosion/maintenance problems can be cited as the most important ones. Furthermore, they are restricted to fixed plants. Therefore, passive fire protection is often used, both for vessels and for structural supports, when the danger of jet fires is considered. A fireproofing layer can delay or even avoid the equipment failure. Townsend et al. [34] performed tests with full-scale rail tank cars containing propane, engulfed in a pool fire. An unprotected tank car equipped with a pressure relief valve (PRV), filled in a 94\%, underwent a powerful BLEVE (content: 40\%) after 24 min; another tank car, also with a PRV, filled in a 85\% and protected with a $3 \mathrm{~mm}$ layer of intumescent paint, BLEVEd (content: 3\%) after $93 \mathrm{~min}$. Therefore, fireproofing can increase the TTF, thus allowing the application of emergency measures such as evacuation. However, the insulating protection can be damaged by erosion, by a mechanical impact as often happens in the case of traffic accidents, or because of the loss of insulating properties at high temperatures, especially in the case of jet fire impingement) [35], the temperature of the unprotected element can increase quickly to dangerous values.

The existence of a PRV should not be considered a protection against failure if a jet fire impinges directly on the non-wetted wall. It will decrease the amount of material involved in the explosion and in the subsequent (if the material is flammable) fireball, although, as commented before, if the emergency lasts a long time the liquid level can decrease significantly, thus increasing the extent of the wall not wetted by the liquid, much prone to failure if there is flames engulfment.

A few authors have proposed the introduction of some high specific surface material (such as aluminium foils) inside the vessel to modify the boiling mechanism, but their efficiency has not been proved.

As a general approach, correlations have been proposed to estimate the time to failure for pressurized vessels [36], even though they should be used only as indicative approaches as their predictions can be modified by specific circumstances.

\section{Conclusions}

From this study the following conclusions can be drawn: 
1) When the first event triggering the domino effect sequence is analyzed for a large set of accidents, fires and explosions have approximately the same contribution; even if fires are more frequent than explosions, the higher reach of explosion effects increases their contribution to domino effect. The same proportion is found when all domino effect steps in the diverse sequences are considered.

2) However, in the case of BLEVE accidents, fire is the prevailing first event, being found in approximately $70 \%$ of cases; when all domino effect steps in the diverse sequences are considered, the fire/explosion proportion is 1.7/1.

3) Approximately half of the accidents associated to the fire $\rightarrow$ BLEVE sequence occurred in transportation.

4) The historical survey has shown that, if there is flame engulfment or impingement, a BLEVE can occur at any moment from the start of the fire, the time to failure ranging between one minute and more than one hour, depending on the circumstances.

5) From the point of view of emergency management, such a situation should therefore be considered as very dangerous; people should be evacuated immediately and firefighters should withdraw to a safe distance.

6) The existence of fireproofing and safety relief valves can contribute -but do not guarantee, especially in the case of mechanical impact- to increase the time to failure. A safety relief valve should not be considered a good protection against vessel failure if a jet fire impinges directly on the vapor surface; however, it reduces the amount of material finally involved in the explosion and in an eventual fireball in the case of flammable materials. These passive protection measures are important, especially in the case of jet fires impingement.

\section{Acknowledgement}

The authors thank the Spanish Ministry of Science and Innovation (project no. CTQ20011-27285) and the Autonomous Government of Catalonia (project No. 2014SGR-413) for sponsoring this research.

\section{References}

[1] Vílchez JA, Sevilla S, Montiel H, Casal J. Historical analysis of accidents in chemical plants and in the transportation of hazardous materials. J. Loss Prev. Process Ind. 1995:8:87-96.

[2] Oggero A, Darbra RM, Muñoz M, Planas E, Casal J. A survey of accidents occurring during the transport of hazardous substances by road and rail. J. Hazard. Mater. 2006:133:1-7.

[3] Darbra RM, Palacios A, Casal J. Domino effect in chemical accidents: main features and accident sequences. J. Hazard. Mater. 2010:183:565-73.

[4] Abdolhamidzadeh B, Abbasi T, Rashtchian D, Abbasi SA. Domino effect in processindustry accidents - An inventory of past events and identification of some patterns. J. Loss Prev. Process Ind. 2011:24:575-93.

[5] Hemmatian B, Abdolhamidzadeh B, Darbra RM, Casal J. The significance of domino effect in chemical accidents. J. Loss Prev. Process Ind.. 2014:29:30-8.

[6] Cozzani V, Gubinelli G, Salzano E. Escalation thresholds in the assessment of domino accidental events. J. Hazard. Mater. 2006:129:1-21.

[7] Johnson A, Cowley L, Health, Safety Executive L. Oil and gas fires characteristics and impact. 1992.Available from: http://hdl.handle.net/10068/667060 
[8] Muñoz M., Arnaldos J, Casal J, Planas E. Analysis of the geometric and radiative characteristics of hydrocarbon pool fires. Combust. Flame. 2004:139:263-77.

[9] Moorhouse J., Pritchard M. J. Thermal radiation hazards from large pool fires and fireballs. A literature review. Institution of Chemical Engineers Symp. Ser. 1982:71:397428.

[10] Pressure-relieving and Depressuring Systems. API STANDARD 521. American Petroleum Institute, 2007.

[11] Mizner G. A., Eyre J. A. Radiation from liquefied gas fires on water. Comb. Sci. Technol. 1983: 35:33-57.

[12] Moodie K, Cowley L. T, Denny R. B, Small L. M, Williams I. Fire engulfment tests on a 5 tonne LPG tank. J. Hazard. Mater. 1988:20:55-71.

[13] Schneider M. E., Kent L. A. Measurements of gas velocities and temperatures in a large open pool fire. Fire Technol. 1989:25:51-80.

[14] Cowley L. T., Johnson A. D. Oil and gas fires-characteristics and impact. OTO 92 596, Health and Safety Executive-HSE. London, 1992.

[15] Roberts T. A., Buckland I., Shirvill L. C., Lowesmith B. J., Salater P. Design snd protection of pressure systems to with stand severe fires. Proc. Saf. Environ. Prot. 2004:82:89-96.

[16] Palacios A., Muñoz M., Darbra R. M., Casal J. Thermal radiation from vertical jet fires. Fire Safety J. 2012:51:93-101.

[17] Casal, J. Evaluation of the effects and consequences of major accidents in industrial plants. Elsevier. Amsterdam, 2008.

[18] Lees FP. Lees' Loss prevention in the process industries: Hazard identification, assessment and control. $2^{\text {nd }}$ ed. Butterworth-Heinemann, 1996.

[19] Mannan S. Lees' Process Safety Essentials. $1^{\text {st }}$. ed. Butterworth-Heinemann, 2014.

[20] Planas-Cuchi E., Casal J., Lancia A., Bordignon L. Protection of equipment eengulfed in a pool fire. J. Loss. Prev. Process Ind. 1996:9:231-240.

[21] Landucci G., Cozzani V., Birk M. Heat radiation effects. In "Domino effects in the process industries, ed. by G. Reniers and V. Cozzani. Elsevier, 2013. Amsterdam.

[22] Major Hazardous Incident Data Service (MHIDAS). In: AEATechnology, editor. London: HSE-Health and Safety Executive (U K). 2007.

[23] ARIA (Analysis, Research and Information on Accidents). (2012). French Ministry of Ecology, Sustainable Development and Energy. Available from: http://barpiaria.preprod.addonline.biz/find-accident/?lang=en. Accessed 12.5.2014.

[24] Major Accident Reporting System (MARS). (2012). Retrieved 10/4/2013, from Major Accident and Hazards Bureau (MAHB) https://emars.jrc.ec.europa.eu/?id=4. Accessed 12.5.2014.

[25] Failure and Accidents Technical Information System (FACTS). (2010). TNO Industrial and External Safety. Available from www.factsonline.nl. Accessed 10.4.2013. [26] CSB (2012). Available from www.csb.gov. Accessed 10.4.2013.

[27] NFPA (2012). Accessed from www.nfpa.org. Accessed 10.4.2013

[28] CCPS. Guidelines for Vapor Cloud Explosion, Pressure Vessel Burst, BLEVE, and Flash Fire Hazards, 2nd ed. AIChE. New York, 2010.

[29] Walls, W. L. What is a BLEVE. Fire J. 31 (1978) 46-47.

[30] Demichela M., Piccinini M., Poggio A. Analysis of an LPG accidental release. Proc. Safety Env. Protect. 2004:82:128-131.

[31] Planas, E., Pastor, E., Casal, J., Bonilla, J. M. Analysis of the boiling liquid expanding vapor explosion (BLEVE) of a liquefied natural gas road tanker: the Zarzalico accident. J. Loss Prev. Process Ind. 2015:34:127-138. 
[32] Badri N, Rad A, Kareshki H, Abdolhamidzadeh B, Parvizsedghy R, Rashtchian D. A risk-based decision making approach to determine fireproofing requirements against jet fires. J. Loss Prev. Process Ind. 2013:26:771-81.

[33] Bradley, I. Severe jet fires and vapor explosions: treatment options and the limitations of the existing guidance are discussed. Hydrocarbon Proc., 2012:May:T85T88.

[34] Townsend W, Anderson C, Zook J, Cowgill G. Comparison of thermally coated and uninsulated rail tank cars filled with LPG subjected to a fire environment (Report FRAOR\&D, 75-32). US Department of Transportation.

[35] Salzano, E., Picozzi, B., Vaccaro, S., Ciambelli, P. Hazard of pressurized tanks involved in fires. Ind. Eng. Chem. Res. 2003:42:1804-1812.

[35] Landucci G, Bubinelli, G., Antonioni, G., Cozzani V. The assessment of the damage probability of storage tanks in domino events triggered by fire. J. Hazard. Mater. 2009:172:447-56. 